\title{
Synthesis of Molecularly Imprinted Polymers for the Selective Extraction of Polymyxins from Environmental Water Samples
}

\author{
Xuqin Song ${ }^{1}$, Esther Turiel ${ }^{2}$, Limin $\mathrm{He}^{1, *(\mathbb{C})}$ and Antonio Martín-Esteban ${ }^{2, *}$ \\ 1 National Reference Laboratory of Veterinary Drug Residues (SCAU), College of Veterinary Medicine, South \\ China Agricultural University, Guangzhou 510642, China; song1991yi@163.com \\ 2 Departamento de Medio Ambiente y Agronomía, INIA, Carretera de A Coruña km 7.5, 28040 Madrid, Spain; \\ turiel@inia.es \\ * Correspondence: liminokhe@scau.edu.cn (L.H.); amartin@inia.es (A.M.-E.); Tel.: +86-20-85280665 (L.H.); \\ +34-91-3478774 (A.M.-E.); Fax: +86-20-85284896 (L.H.); +34-91-3474008 (A.M.-E.)
}

Received: 27 February 2020; Accepted: 28 February 2020; Published: 8 March 2020

check for updates

The authors wish to make a change to the published paper [1]. In the original manuscript, there are mistakes in the headers of columns six and seven in Table 1 . The corrected Table 1 is presented below.

Table 1. Accuracy, precision, limit of detection and limit of quantification of colistin A, colistin B and polymyxin $B$ from different kinds of water samples spiked with the mixture of target analytes (10 $\mathrm{g} \mathrm{L}^{-1}$ for each) after MISPE treatment.

\begin{tabular}{|c|c|c|c|c|c|c|c|}
\hline \multirow{2}{*}{ Water Source } & \multirow{2}{*}{ Analyte $^{a}$} & \multicolumn{3}{|c|}{ Intra-Day Recovery $\left(\mathrm{RSD}^{b}, \%, \mathrm{n}=3\right)$} & \multirow{2}{*}{$\begin{array}{c}\text { Inter-Day Recovery } \\
(\mathrm{RSD}, \%, \mathrm{n}=9)\end{array}$} & \multirow{2}{*}{$\begin{array}{c}\operatorname{LOD}^{C} \\
\left(\mu \mathrm{g} \mathrm{L}^{-1}\right)\end{array}$} & \multirow{2}{*}{$\begin{array}{r}\mathrm{LOQ}^{d} \\
\left(\mu \mathrm{g} \mathrm{L}^{-1}\right)\end{array}$} \\
\hline & & I & II & III & & & \\
\hline \multirow[t]{3}{*}{ River } & CSA & $74.7(3.7)$ & $65.9(4.5)$ & $75.7(3.2)$ & $72.1(7.3)$ & 2.0 & 6.5 \\
\hline & CSB & $77.2(3.6)$ & $72.1(3.8)$ & $72.1(1.9)$ & $73.8(4.6)$ & 1.5 & 5.0 \\
\hline & PMB & $83.7(3.2)$ & $76.9(9.7)$ & $83.6(1.4)$ & $81.4(6.3)$ & 1.0 & 3.0 \\
\hline \multirow[t]{3}{*}{ Spring } & CSA & $72.3(2.1)$ & $71.6(4.7)$ & $76.8(1.2)$ & $73.6(4.2)$ & 1.0 & 3.0 \\
\hline & CSB & $74.6(2.2)$ & $81.8(3.9)$ & $74.4(3.0)$ & $76.9(5.5)$ & 1.0 & 3.0 \\
\hline & PMB & $85.5(5.3)$ & $83.1(4.3)$ & $80.9(10.2)$ & $83.2(6.4)$ & 1.0 & 3.0 \\
\hline \multirow[t]{3}{*}{ Lake } & CSA & $83.1(3.9)$ & $84.4(6.2)$ & $86.4(9.5)$ & $84.6(6.3)$ & 2.0 & 6.0 \\
\hline & CSB & $85.6(3.7)$ & $86.7(2.3)$ & $85.1(3.6)$ & $85.8(3.1)$ & 1.5 & 5.0 \\
\hline & PMB & $83.8(3.1)$ & $90.1(1.8)$ & $84.5(2.3)$ & $86.2(4.0)$ & 1.0 & 3.0 \\
\hline
\end{tabular}

${ }^{a}$ Colistin A (CSA); colistin B (CSB); polymyxin B (PMB); ${ }^{b}$ relative standard deviation (RSD); ${ }^{c}$ limit of detection (LOD); ${ }^{d}$ limit of quantification (LOQ).

The authors apologize for any inconvenience caused and the change does not affect the scientific results. The manuscript will be updated, and the original will remain online on the article webpage at https://www.mdpi.com/2073-4360/12/1/131.

\section{References}

1. Song, X.; Turiel, E.; He, L.; Martín-Esteban, A. Synthesis of Molecularly Imprinted Polymers for the Selective Extraction of Polymyxins from Environmental Water Samples. Polymers 2020, 12, 131. [CrossRef] [PubMed]

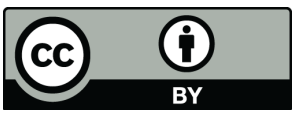

(C) 2020 by the authors. Licensee MDPI, Basel, Switzerland. This article is an open access article distributed under the terms and conditions of the Creative Commons Attribution (CC BY) license (http://creativecommons.org/licenses/by/4.0/). 